\title{
Upstream logistic transport planning in the oil-industry: a case study
}

\author{
Diego G. Rossit ${ }^{a^{*}}$, Mauro Ehulech Gonzalez ${ }^{\mathrm{b}}$, Fernando Tohméc and Mariano Frutos ${ }^{\mathrm{d}}$
}

${ }^{a} I N M A B B$, Department of Engineering, Universidad Nacional del Sur (UNS)-CONICET, Alem Avenue 1253, Bahía Blanca, 8000, Argentina

${ }^{b}$ Bolland y Cía S.A., Del Progreso Avenue 6705, Comodoro Rivadavia, 9000, Argentina

'INMABB, Department of Economics, Universidad Nacional del Sur (UNS)-CONICET, Alem Avenue 1253, Bahía Blanca, 8000, Argentina

${ }^{d}$ IIESS, Department of Engineering, Universidad Nacional del Sur (UNS)-CONICET, Alem Avenue 1253, Bahía Blanca, 8000, Argentina

\section{H R O N I C L E}

\section{Article history:}

Received June 182019

Received in Revised Format

August 52019

Accepted August 52019

Available online

September 82019

Keywords:

Decision support tools

Oil industry

Upstream logistics

Inland transportation

\section{Introduction}

The oil industry handles large amounts of money, either in investments or expected revenues. However, in an increasingly competitive world with new public regulations and an increasing environmental awareness, companies feel the pressure to enhance their efficiency by refining their processes (Ebrahimi et al., 2018). One area in which this is crucial is transport logistics (Hussain et al., 2006). Logistic activities in the oil industry can be classified in two main categories (Aas et al., 2007): upstream logistics, which involves providing the facilities (mainly oil wells) with supplies needed to extract oil; and downstream logistics, which is aimed towards bringing the extracted oil and gas to consumers. Upstream logistics is an area that has not yet been thoroughly researched (Aas et al., 2009). Moreover, the largest part of the literature on upstream logistic, has focused on offshore production and on routing of vessels (see, e.g., Aas et al., 2007; Fagerholt and Lindstad, 2000; Halvorsen-Weare et al., 2012). This paper focuses, instead, on the upstream logistics of the inland operations of a SME (Small and Medium Enterprise) company providing supplies on-site for oil extraction of a client oil company in Argentina.

* Corresponding author Tel.: +54(9291)4595001 (Ext: 3233)

E-mail: diego.rossit@uns.edu.ar (D. G. Rossit)

2020 Growing Science Ltd

doi: $10.5267 /$ j.ijiec.2019.9.002 
As in any supply chain, the amounts and quality of inputs should be delivered with regularity to avoid disruptions in the production process. However, managers that have to plan distribution activities in this context has to deal with several obstacles based on customers' requirements. For example, the demand is scattered over hundreds of facilities that have to be served with different kinds of products; the schedules of drivers of the trucks involved in these distribution trips are regulated by strong labor conventions; and the distances on the actual road network are barely known. Currently, managers design the distribution schedules mainly based on their experience. But the efficiency of distribution plan is not the only goal that matters; the time that takes to present a solution to a client is equally important to increase the client satisfaction.

This work proposes a decision support tool which aims to systematize the process of building a distribution schedule to reduce the time spent in constructing a feasible schedule of provision of chemical supplies to numerous facilities distributed on a large area, making operational decisions at the level of day-to-day logistics (Dempster et al., 2000). The facilities include not only the oil wells but also the related installations used to extract and transport oil. A resolution method for this problem is developed. This work is structured as follows. In Section 2, the target problem is described and the related literature is discussed. In Section 3, a mathematical formulation and a constructive heuristic for this problem are presented. Section 4 presents the main results while Section 5 concludes, discussing possible future work.

\section{Problem description}

The problem under consideration arises in the upstream logistic supply chain of a company located in southern Argentina. A certain number of products used as inputs in the facilities have to be distributed to several locations. These products are used with various purposes, e.g., for enhancing the flow through pipelines by reducing corrosion, preventing the sedimentation of organic material, such as paraffins and asphaltenes, and the incrustations of bacteria and calcium carbonate, increasing the lifespan of the facilities. A correct supply of these products is required in order to ensure a steady provision of oil. This setting exhibits certain features that make it an interesting real-world problem:

- Demand sites. The demand nodes, i.e., the facilities that have to be served, are not static, problem under consideration particular cases of volatile behavior in the supply chain (Nitsche \& Durach, 2018). The location of facilities can vary regularly depending on changes in the operational conditions that may lead to those displacements. The latter are usually due to the required quality of oil, as the differences in temperature, pressure or the proportion of water content. Although the staff of the operational system knows the location of the facilities at ground level (this is necessary for the provision of proper services), the staff at a more tactical level usually lacks this information since the number of facilities is large, the frequency of modifications is high and the personnel is scarce, preventing the company from geo-localizing the facilities and the network of paths connecting them. This data can only be estimated.

- Maximum travel times. Mainly because of the specificity of the job, the workforce has certain benefits not shared with workers in other areas. Although Argentinean oil industry workers enjoy some extra special conditions (Lopez Cattaneo, 2009), they do not differ much from those in other parts of the world (Brešić et al., 2007). In terms of the problem analyzed in this paper, these conditions affect the maximum allowable travel time for drivers, as specified by labor conventions.

- Drivers and heterogeneous fleets. The company has a fleet of three trucks, one which has a larger capacity than the others. But since just two drivers are available, only two trucks can be used simultaneously. The products are distributed in barrels of 200 liters, where each barrel contains only one kind of product. While the capacity of the vehicles is measured in barrels, the demand of the products in the facilities is expressed in liters.

- Safeness restrictions. Due to safety restrictions, some products cannot be loaded on the same truck (even if they are in different barrels). Hereafter, two sites are "compatible" if the products 
demanded by them can be loaded on the same truck. The magnitude of the daily consumption of products at the facilities varies considerably between different facilities.

- Facilities storage capacity. The storage capacity in each facility differs from that in the others. Obviously, a facility cannot receive load than what it is allowed by its storage capacity.

The company solves this problem on an everyday basis. The staff designs the routes as to build clusters of nearby facilities demanding compatible products. This activity is extremely time consuming, considering that the number of facilities is quite large. The travel time on a route is estimated by the company using an empirical formula. Let $I=\left\{i_{1}, \ldots, i_{|I|}\right\}$ be the set of facilities. Then, the experience indicates that the on-the-road travel time on a route $r$ is given by Eq. (1):

$$
T_{r}=\frac{\left(4 D_{\max }+\left|I_{r}\right|\right)}{V}+Q v b+\sum_{i \in I} s_{i}
$$

where $D_{\max }$ is the distance to the farthest "base" in meters. A "base" is a larger facility located in a certain region, responsible for providing essential services to smaller facilities in the same region. $I_{r}$ is the set of facilities visited by route $r . V$ is the average velocity of the vehicle in meters per minute. $Q$ is the total demand of the route in liters. $v b$ is the loading speed of the pump at the depot in liters per minute (therefore, $Q v b$ represents the length of time devoted to upload the supplies to be distributes along the route). Once the vehicle has reached a facility $i, s_{i}$ is the time, measured in minutes, that takes to offload the supply from the vehicle to the tanks in the facility. The company seeks to improve the scheduling process in two ways: reducing the time dedicated to build the schedule and improving the quality and precision of the information used in building the schedule. The satisfaction of the first requirement depends on the responsiveness of the supply chain strategy. In the current context, since the company works for several days to develop a supply schedule, the possibility of adapting rapidly to changing customer needs and changing market demands is severely compromised (Fera et al., 2017; Gligor et al., 2019). The second requirement amounts to collecting information useful to improve the estimation of travel times of the trucks. This problem has certain characteristics that differentiates it from others analyzed in the literature. In the next Section a review of some related works, including the applications of decision support systems in the transportation activities of the oil industry, is performed as to better understand the specificities of the problem under analysis.

\subsection{Related Work}

Although the design of supply distribution plans in the upstream logistics of the oil industry has not been usually addressed in the literature (Aas et al., 2009), there exist some studies in the field. Most of them present study cases in the Norwegian oil industry, involving the offshore extraction of oil and dealing with maritime routing plans. Fagerholt and Lindstad (2000) presented an optimal routing policy for a fleet of supply vessels serving several offshore installations up from one onshore base. The solution is obtained using a two stages procedure. First, feasible candidate schedules are generated for each vessel by solving a set of Travelling Salesman Problems (TSP) using dynamic programming. Then, in the second stage, an integer programming model is used to define the week plan choosing among the previously generated schedules. The robustness of solutions is assessed with a sensitivity analysis in which the opening hours at which offshore installations can receive supply vessels are varied. A similar analysis yields the solution of a vessel routing problem in Halvorsen-Weare et al. (2012), where the problem of routing vessels is again divided in two similar stages. The first stage consists of enumerating the potential vessel schedules and the second stage that generates the weekly plan using integer programming. Aas et al. (2007) solved a pickup and delivery routing problem for supply vessels serving offshore installations at Haltenbanken, off the Northwest coast of Norway. They present a mixed-integer programming model optimizing the route of one vessel, considering the offshore installations storage capacity. They found that efficiency of the route depends crucially on this capacity. 
One important feature common to these works is the relatively small number of demand sites. For example, Fagerholt and Lindstad (2000), Aas et al. (2007) and Halvorsen-Weare et al. (2012) considered seven, ten and fourteen demand points, respectively. This allowed them to find exact solutions to their problems. In recent years some works have introduced competitive heuristics to deal with larger instances. For example, Kisialiou et al. (2018a) used an Adaptive Large Neighborhood Search (LNS) to solve a maritime routing problem while considering different possible departures times with real instances of up to 31 installations. A similar study with LNS was carried out in Shyshou et al. (2012). Cuesta et al. (2017) used the same approach to simultaneously determine the routes of multiple vessels in instances up to 60 offshore platforms. Uncertainty has been also considered in the context of this problem, mainly related to weather conditions affecting the service and travel times (see, e.g., Kisialiou et al., 2018b; Maisiuk \& Gribkovskaia, 2014). While, as said, the majority of these applications were developed to solve Norwegian cases, there are a few analyzing similar offshore distribution problems in Brazil (Friedberg \& Uglane, 2013), Mexico (Kaiser, 2010) and Russia (Milaković et al., 2015). While offshore provision problems have been, as indicated, solved in various guises, there are no, as far as we know, applications of decision support tools to inland transport operations in the oil industry. Moreover, there has been done comparatively little research on real-world supply chain problems in Latin American countries, other than those in agricultural production processes (Fritz \& Silva, 2018).

\subsection{Solution approach}

The problem addressed in this paper involves many complicated real-world constraints. The requirement of the company, namely to improve the formula for estimating the travel time (Eq. (1)), was addressed with a partial digitalization of the regional distribution of sites. The full digitalization of the individual facilities and of the network of paths between them is out of question due to the large number of elements involved (the large quantity of sites can be seen in Fig. 1). Moreover, since these facilities vary constantly, this information, which requires a lot of effort to be obtained, becomes obsolete in a short period of time. Instead, the bases, which are more stable, were geo-localized the QGIS software. This allowed us to improve the original empirical formula of estimation of travel times: when a route includes facilities supplied by two different bases, the Euclidean distance between those bases is added. In fact, since more than two bases can be included in one tour, the solution of the Euclidean TSP of the bases included in $r$ $\left(B_{r}\right)$ and the main depot, i.e., $T S P_{B_{r} \cup \text { depot }}$, is calculated. The resulting expression is:

$$
T_{r}=V\left(4 D_{\text {max }}+\left|I_{r}\right|\right)+Q v b+\sum_{i \in I} s_{i}+T S P_{B_{r} \cup \text { depot }} \text {. }
$$

Then, the other requirement of the company, namely reducing the time to build a schedule, is addressed by the design of a constructive heuristic which uses the aforementioned formula and aims to minimize the planning horizon. Thus, to further describe the problem addressed in this work, first, a mathematical formulation is presented in Section 3.1 and, then, in Section 3.2 the constructive heuristic for solving the model is devised.

\subsection{Mathematical formulation}

A mathematical formulation that aims to minimize the number of days required for fulfilling the supply of the products to the facilities is presented. The proposed formulation has the following sets and parameters:

- I: set of facilities (demand points).

- $B$ : set of bases without the depot.

- $B^{0}$ : set of bases including the depot, $B^{0}=B \cup$ depot.

- $I^{b}$ : subset of facilities that belong to base $b \in B$.

- $K$ : set of types of products.

- $L$ : set of vehicles.

- $D$ : set of days in the week.

and the following parameters: 
- $V$ : average speed of the vehicles.

- $v b$ : loading speed of the pump at the depot.

- $q_{k i}$ : amount of product $k$ required by facility $i$ in liters.

- $s_{i}$ : service time required by facility $i$.

- $C_{l}$ : capacity in barrels of vehicle $l$.

- $T_{\text {max }}$ : maximum allowable route time.

- $w_{k b^{\prime}}$ : a binary parameter that is 1 if products $k$ and $k^{\prime \prime}$ are compatible, 0 otherwise.

- $\operatorname{dist}_{b b^{\prime}}$ : distance between bases $b$ and $b^{\prime}$.

Then, formulation has the following variables:

- $Q_{k l d}$ : number of barrels of product $k$ in vehicle $l$ on day $d$.

- $t_{l d}$ : distance to the facility that is served by vehicle $l$ on day $d$.

- $x_{i l d}: 1$ if vehicle $l$ serves the facility $i$ on day $d, 0$ otherwise.

- $H$ : makespan of the planning horizon.

- $y_{b^{\prime} b}^{l d}: 1$ if vehicle $l$ serves the facility $b \in B^{0}$ after base $b^{\prime} \in B^{0}$ on day $d, 0$ otherwise.

- $\quad p_{b}^{l d}: 1$ if vehicle $l$ on day $d$ serves base $b \in B, 0$ otherwise.

- $u_{b}^{l d}$ : continue variable for subtour elimination in the TSP.

Then, the mathematical formulation can be outlined as:

$\min H$

subject to:

$$
\begin{aligned}
& \sum_{l \in L} x_{i l d} d \leq H, \forall i \in I, d \in D \\
& \sum_{\substack{l \in L \\
d \in D}} x_{i l d}=1, \forall i \in I
\end{aligned}
$$

$Q_{k l d} \geq \frac{\sum_{i \in I} q_{k i} x_{i l d}}{200}, \forall k \in K, l \in L, d \in D$

$Q_{k_{1} l d} Q_{k_{2} l d} \leq w_{k_{1} k_{2}} C_{l}^{2}, \forall k_{1}, k_{2} \in K, k_{1} \neq k_{2}, l \in L, d \in D$

$C_{l} \geq \sum_{k \in K} Q_{k l d}, \forall l \in L, d \in D$,

$t_{l d} \geq p_{b}^{l d}$ dist $_{b d e p}, \forall l \in L, d \in D, b \in B$

$T_{\text {max }} \geq V\left(\sum_{i \in I} x_{i l d}+4 t_{l d}\right)+\sum_{i \in I}\left(\sum_{k \in K} q_{k i} v b+s_{i}\right) x_{i l d}+\sum_{\substack{b \in B^{0} \\ b^{\prime} \in B^{0}, b^{\prime} \neq b}} \operatorname{dist}_{b b^{\prime}} y_{b b^{\prime}}^{l d}, \forall l$

$|I| p_{b}^{l d} \geq \sum_{i \in I^{b}} x_{i l d}, \forall l \in L, d \in D, b \in B$

$p_{b}^{l d} \leq \sum_{i \in I^{b}} x_{i l d}, \forall l \in L, d \in D, b \in B$ 


$$
\begin{aligned}
& |I| p_{\text {depot }}^{l d} \geq \sum_{i \in I} x_{i l d}, \forall l \in L, d \in D \\
& p_{\text {depot }}^{l d} \leq \sum_{i \in I} x_{i l d}, \forall l \in L, d \in D \\
& \quad \sum_{b^{\prime} \in B^{0}, b^{\prime} \neq b} y_{b b^{\prime}}^{l d}=p_{b}^{l d}, \forall l \in L, d \in D, b \in B^{0} \\
& \quad \sum_{b^{\prime} \in B^{0}, b^{\prime} \neq b} y_{b^{\prime} b}^{l d}=p_{b}^{l d}, \forall l \in L, d \in D, b \in B^{0} \\
& u_{b}^{l d}-u_{b^{\prime}}^{l d}+\sum_{b^{\prime \prime} \in B^{0}}\left(p_{b^{\prime \prime}}^{l d}\right) y_{b^{\prime} b}^{l d} \leq \sum_{b^{\prime \prime} \in B^{0}}\left(p_{b^{\prime \prime}}^{l d}\right)-1, \forall l \in L, d \in D, b, b^{\prime} \in B^{0}, b^{\prime} \neq b \\
& 0 \leq u_{b}^{l d} \leq \sum_{b^{\prime} \in B^{0}}\left(p_{b^{\prime}}^{l d}\right)-1, \forall l \in L, d \in D, b \in B^{0} \\
& t_{l d} \geq 0, \forall l \in L, d \in D \\
& Q_{k l d} \in \mathbb{Z}_{0}^{+}, \forall k \in K, l \in L, d \in D \\
& H \in \mathbb{Z}_{0}^{+} \\
& x_{i l d} \in\{0,1\}, \forall i \in I, l \in L, d \in D \\
& y_{b^{\prime} b}^{l d} \in\{0,1\}, \forall b, b^{\prime} \in B^{0}, l \in L, d \in D \\
& p_{b}^{l d} \in\{0,1\}, \forall b \in B^{0}, l \in L, d \in D
\end{aligned}
$$

Eq. (3) aims to minimize the time horizon makespan. Eq. (4) fixes the makespan of the planning horizon to the last day that a vehicle is used. Eq. (5) indicates that a facility can only be assigned to one trip. Eq. (6) establishes the load per product in number of barrels for each trip. Eq. (7) ensures that two incompatible products cannot be included in the same trip. Eq. (8) limits the amount of barrels per trip to the capacity of the vehicle. Eq. (9) fixes the furthest base from the depot that is visited on each trip. Eq. (10) enforces the duration of each trip to less than the allowable time limit estimated by the proposed formula, which includes the solution of the TSP (hereafter "tour") between the bases that are included and the depot. Eq. (11) and (12) enforces that if a facility from a base is included in trip, that base is considered for the TSP tour. Eq. (13) and (14) enforces that if a facility is included in trip, the depot is considered for the TSP tour. Eq. (15) and (16) enforces that if a base is included in trip, it is visited and left just once in the TSP tour. Eq. (17) and (18) are the subtour elimination constraints for the TSP according to the Miller-Tucker-Zemlin formulation for the TSP (Miller et al., 1960). Eq. (19) establishes the non-negative continuous nature of the variable. Eqs. (20) and (21) define the non-negative integer nature of the variables. Finally, Eqs. (22) to (24) establish the binary nature of variables.

\subsection{Heuristic}

In real-life problems, where large-dimension search spaces and/or a variety of hard constraints are included, classical exact solution methods can be highly time-consuming (Nesmachnow, 2014; Toncovich et al., 2019). Therefore, designing heuristics can be a valuable approach for constructing fast feasible solutions. In this work, a three-stage constructive heuristic for the addressed transportation problem is devised. This heuristic allows reducing the time invested in building a schedule and, therefore, increases the flexibility of the company to coup with changes in its client's demand and enhance customer satisfaction (Singh et al., 2018). The first stage involves conforming "clusters" of facilities corresponding to the same base and requiring the same product, respecting the requeriments on the maximum travel 
time and the capacity of the trucks. Despite being a simple procedure, it allows us to reduce considerably the size of the problem. The second stage consists in designing the routes, satisfying the constraints on maximum allowable traveling time, the capacity and the incompatibility restrictions. First, a route is initiated by selecting the unassigned cluster with the largest demand, the so-called "seed" cluster. Then, the algorithm iteratively adds to the route the unassigned cluster with the next largest demand compatible with the seed cluster, belonging to the same base. This is repeated until the capacity of the route is fulfilled, either by reaching the maximum allowable time or the maximum vehicle capacity, or alternatively, there is no feasible extra addition. If the latter is the case, the algorithm adds the compatible unassigned cluster with largest demand belonging to the base that is closest to the base of the seed cluster. The distance between bases is approximated by the Euclidean distance. This is repeated until, again, either the maximum value of time or capacity is reached. At that point the route is completed. Then, a new route is started and the procedure is reiterated. These steps are repeated until all the clusters are assigned to a route. When constructing the routes, the focus is on maximizing the usage of the truck with the largest capacity but also on balancing the times the two different truck capacities are used, i.e., if all the routes require the largest truck, one driver (and two trucks) will remain idle and the schedule horizon will be too long. Finally, in the third stage, the routes are scheduled in a temporal horizon, i.e., they are assigned to a certain truck and driver. The pseudo code algorithm of the entire procedure is as follows:

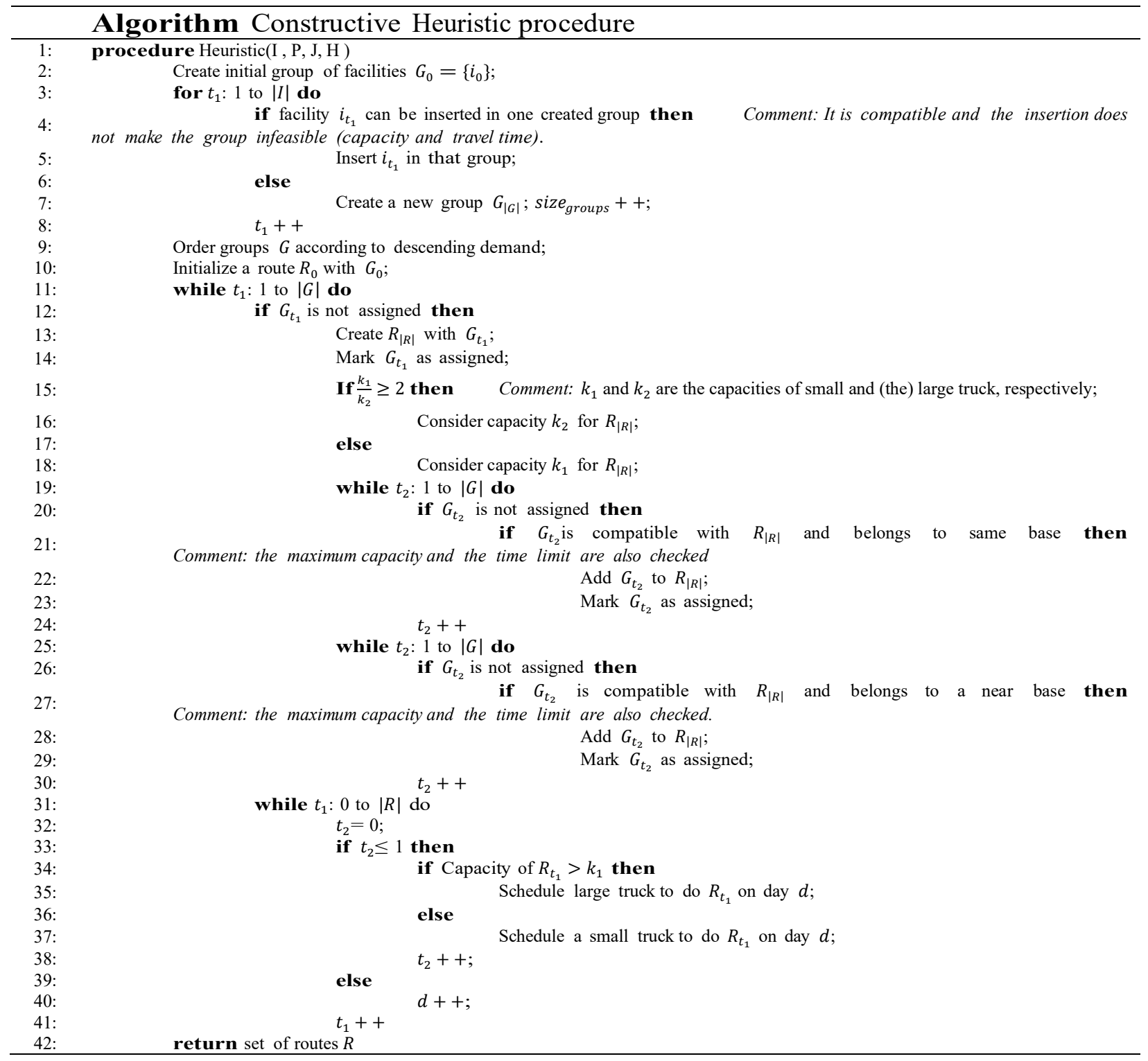




\section{Experiments}

In this Section the results of solving two real instances of the company with the constructive heuristic are presented. These are Instance I and Instance II. Both instances involve the set of complex real-world constraints described in Section 2 and the aim is to design the monthly schedule. These instances are based on what the company called as "LMLP DIVISION", represented in Fig. 1, which is one of the largest regions where the company operates. The products that are used and system codes assigned to the products are presented in Table 1. As mentioned before, if two products share the same system code, they can be transported in the same trip. The heuristic was coded in $\mathrm{C}++$. The Euclidean TSP included in Eq. (2) was solved with the Lin-Kernighan-Helsgaun heuristic (Helsgaun, 2000; Lin and Kernighan, 1973). As indicated, there are three trucks available for dispatching the products with capacities of 26 , 26 and 28 barrels, respectively. Each barrel has, as said, a capacity of 200 lts. The time limit of the workday set by labor conventions is $450 \mathrm{~min}$.

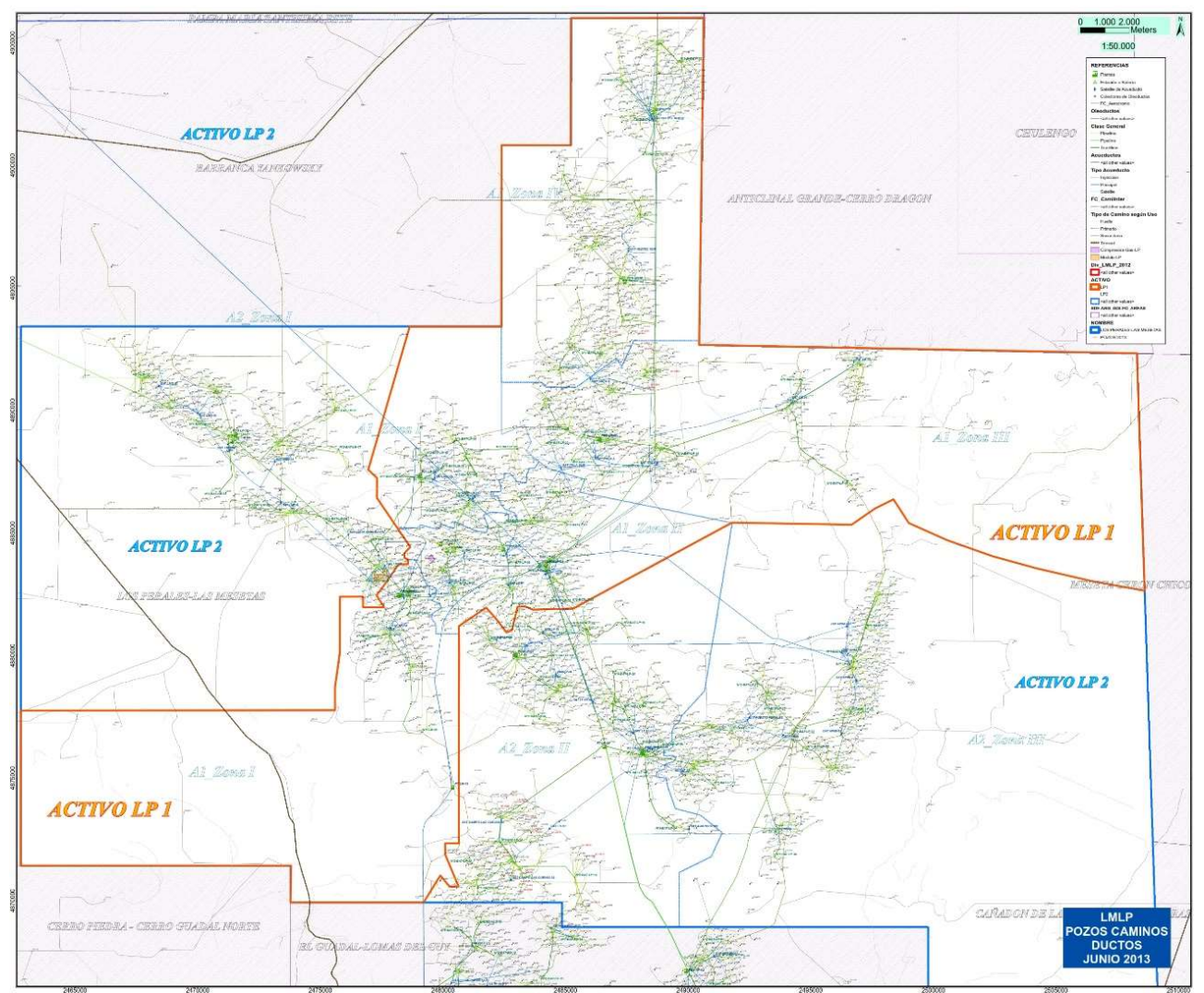

Fig. 1. Map of area under consideration

Table 1

Chemical products for both instances.

\begin{tabular}{|c|c|c|c|}
\hline Product Code & System Code & Product Code & System Code \\
\hline $\mathrm{P}_{1}$ & 0 & $\mathrm{P}_{11}$ & 3 \\
\hline $\mathrm{P}_{2}$ & 1 & $\mathrm{P}_{12}$ & 3 \\
\hline $\mathrm{P}_{3}$ & 3 & $\mathrm{P}_{13}$ & 0 \\
\hline $\mathrm{P}_{4}$ & 3 & $\mathrm{P}_{14}$ & 0 \\
\hline $\mathrm{P}_{5}$ & 3 & $\mathrm{P}_{15}$ & 0 \\
\hline $\mathrm{P}_{6}$ & 3 & $\mathrm{P}_{16}$ & 0 \\
\hline $\mathrm{P}_{7}$ & 0 & $P_{17}$ & 2 \\
\hline $\mathrm{P}_{8}$ & 0 & $\mathrm{P}_{18}$ & 2 \\
\hline $\mathrm{P}_{9}$ & 0 & $\mathrm{P}_{19}$ & 0 \\
\hline $\mathrm{P}_{10}$ & 3 & & \\
\hline
\end{tabular}




\subsection{Instance I}

This instance includes 742 facilities demanding eighteen different chemical products with four system codes. In the first clustering phase of the heuristic, 236 clusters are conformed. The second phase of the heuristic yields 54 routes. In Table 2 information about each route is outlined, particularly the number of facilities that are included, the total time required, the total service time on the route (required to unload the product in the facilities), the driving time, the time necessary to load the truck at the depot, the number of barrels carried on the truck, the system codes of the products included, and the number of different products delivered.

Table 2

Description of routes in solution of Instance I

\begin{tabular}{|c|c|c|c|c|c|c|c|c|}
\hline Route & $\begin{array}{c}\text { Number of } \\
\text { facilities }\end{array}$ & $\begin{array}{l}\text { Total time } \\
\text { (min) }\end{array}$ & $\begin{array}{l}\text { Service time } \\
\quad(\text { min })\end{array}$ & $\begin{array}{l}\text { Transport } \\
\text { time (min) }\end{array}$ & $\begin{array}{c}\text { Loading } \\
\text { time (min) }\end{array}$ & $\begin{array}{l}\text { Demand in } \\
\text { barrels }\end{array}$ & $\begin{array}{l}\text { System } \\
\text { Code }\end{array}$ & $\begin{array}{c}\text { Number of } \\
\text { products }\end{array}$ \\
\hline 1 & 1 & 383 & 186 & 57 & 140 & 28 & 1 & 1 \\
\hline 2 & 1 & 428 & 155 & 153 & 120 & 24 & 1 & 1 \\
\hline 3 & 1 & 428 & 155 & 153 & 120 & 24 & 1 & 1 \\
\hline 4 & 16 & 443 & 171 & 137 & 135 & 27 & 0 & 3 \\
\hline 5 & 23 & 448 & 160 & 163 & 125 & 25 & 0 & 3 \\
\hline 6 & 11 & 449 & 142 & 197 & 110 & 22 & 0 & 2 \\
\hline 7 & 19 & 442 & 131 & 211 & 100 & 20 & 0 & 2 \\
\hline 8 & 22 & 448 & 163 & 154 & 130 & 26 & 0 & 3 \\
\hline 9 & 26 & 445 & 142 & 189 & 115 & 23 & 0 & 5 \\
\hline 10 & 1 & 206 & 103 & 22 & 80 & 16 & 1 & 1 \\
\hline 11 & 1 & 206 & 103 & 22 & 80 & 16 & 1 & 1 \\
\hline 12 & 1 & 199 & 103 & 15 & 80 & 16 & 1 & 1 \\
\hline 13 & 1 & 199 & 103 & 15 & 80 & 16 & 1 & 1 \\
\hline 14 & 1 & 281 & 103 & 98 & 80 & 16 & 1 & 1 \\
\hline 15 & 1 & 281 & 103 & 98 & 80 & 16 & 1 & 1 \\
\hline 16 & 19 & 447 & 177 & 135 & 135 & 27 & 0 & 2 \\
\hline 17 & 15 & 449 & 161 & 163 & 125 & 25 & 0 & 3 \\
\hline 18 & 22 & 443 & 157 & 161 & 125 & 25 & 0 & 4 \\
\hline 19 & 19 & 417 & 176 & 101 & 140 & 28 & 0 & 3 \\
\hline 20 & 21 & 444 & 158 & 166 & 120 & 24 & 0 & 2 \\
\hline 21 & 18 & 447 & 172 & 141 & 135 & 27 & 0 & 3 \\
\hline 22 & 15 & 380 & 162 & 87 & 130 & 26 & 0 & 3 \\
\hline 23 & 9 & 442 & 129 & 207 & 105 & 21 & 0 & 3 \\
\hline 24 & 22 & 447 & 162 & 154 & 130 & 26 & 0 & 2 \\
\hline 25 & 21 & 411 & 180 & 91 & 140 & 28 & 0 & 3 \\
\hline 26 & 20 & 437 & 163 & 144 & 130 & 26 & 0 & 2 \\
\hline 27 & 11 & 443 & 125 & 218 & 100 & 20 & 0 & 2 \\
\hline 28 & 21 & 445 & 152 & 173 & 120 & 24 & 0 & 4 \\
\hline 29 & 7 & 448 & 83 & 300 & 65 & 13 & 0 & 2 \\
\hline 30 & 19 & 449 & 118 & 231 & 100 & 20 & 0 & 5 \\
\hline 31 & 19 & 445 & 169 & 135 & 140 & 28 & 0 & 5 \\
\hline 32 & 19 & 443 & 117 & 231 & 95 & 19 & 0 & 3 \\
\hline 33 & 27 & 433 & 178 & 115 & 140 & 28 & 0 & 3 \\
\hline 34 & 8 & 381 & 168 & 82 & 130 & 26 & 3 & 4 \\
\hline 35 & 23 & 378 & 178 & 60 & 140 & 28 & 0 & 3 \\
\hline 36 & 18 & 440 & 143 & 182 & 115 & 23 & 0 & 4 \\
\hline 37 & 16 & 444 & 116 & 233 & 95 & 19 & 0 & 4 \\
\hline 38 & 7 & 446 & 158 & 163 & 125 & 25 & 3 & 4 \\
\hline 39 & 13 & 449 & 128 & 221 & 100 & 20 & 0 & 4 \\
\hline 40 & 10 & 415 & 166 & 113 & 135 & 27 & 3 & 6 \\
\hline 41 & 8 & 441 & 123 & 213 & 105 & 21 & 3 & 5 \\
\hline 42 & 22 & 448 & 107 & 250 & 90 & 18 & 0 & 5 \\
\hline 43 & 10 & 432 & 131 & 195 & 105 & 21 & 0 & 3 \\
\hline 44 & 8 & 448 & 141 & 192 & 115 & 23 & 3 & 4 \\
\hline 45 & 13 & 449 & 168 & 146 & 135 & 27 & 0 & 4 \\
\hline 46 & 27 & 400 & 162 & 108 & 130 & 26 & 0 & 3 \\
\hline 47 & 33 & 424 & 152 & 153 & 120 & 24 & 0 & 2 \\
\hline 48 & 23 & 449 & 96 & 273 & 80 & 16 & 0 & 2 \\
\hline 49 & 7 & 444 & 109 & 245 & 90 & 18 & 3 & 4 \\
\hline 50 & 19 & 403 & 72 & 266 & 65 & 13 & 0 & 3 \\
\hline 51 & 5 & 74 & 25 & 29 & 20 & 4 & 0 & 1 \\
\hline 52 & 13 & 450 & 110 & 255 & 85 & 17 & 2 & 1 \\
\hline 53 & 6 & 314 & 62 & 202 & 50 & 10 & 2 & 1 \\
\hline 54 & 3 & 242 & 18 & 204 & 20 & 4 & 3 & 3 \\
\hline
\end{tabular}


The proposed schedule is reported in Table 3, which, for each day, indicates the route followed by each truck. Trucks T1 and T2 are the ones with a capacity of 26 barrels, while truck T3 has a capacity of 28 barrels.

Table 3

Solution of Instance I

\begin{tabular}{|c|c|c|c|c|}
\hline \multirow{2}{*}{ Day } & \multirow{2}{*}{ Route } & \multicolumn{3}{|c|}{ Truck } \\
\hline & & T1 & T2 & T3 \\
\hline \multirow{2}{*}{1} & 1 & & & 1 \\
\hline & 2 & 1 & & \\
\hline \multirow{2}{*}{2} & 3 & 1 & & \\
\hline & 4 & & & 1 \\
\hline \multirow{2}{*}{3} & 5 & 1 & & \\
\hline & 6 & & 1 & \\
\hline \multirow{2}{*}{4} & 7 & 1 & & \\
\hline & 8 & & 1 & \\
\hline \multirow{2}{*}{5} & 9 & 1 & & \\
\hline & 10 & & 1 & \\
\hline \multirow{2}{*}{6} & 11 & 1 & & \\
\hline & 12 & & 1 & \\
\hline \multirow[b]{2}{*}{7} & 13 & 1 & & \\
\hline & 14 & & 1 & \\
\hline \multirow{2}{*}{8} & 15 & 1 & & \\
\hline & 16 & & & 1 \\
\hline \multirow{2}{*}{9} & 17 & 1 & & \\
\hline & 18 & & 1 & \\
\hline \multirow{2}{*}{10} & 19 & & & 1 \\
\hline & 20 & 1 & & \\
\hline \multirow{2}{*}{11} & 21 & & & 1 \\
\hline & 22 & 1 & & \\
\hline \multirow{2}{*}{12} & 23 & 1 & & \\
\hline & 24 & & 1 & \\
\hline \multirow{2}{*}{13} & 25 & & & 1 \\
\hline & 26 & 1 & & \\
\hline \multirow{2}{*}{14} & 27 & 1 & & \\
\hline & 28 & & 1 & \\
\hline
\end{tabular}

\begin{tabular}{|c|c|c|c|c|}
\hline \multirow{2}{*}{ Day } & \multirow{2}{*}{ Route } & \multicolumn{3}{|c|}{ Truck } \\
\hline & & T1 & $\mathbf{T} 2$ & T3 \\
\hline \multirow{2}{*}{15} & 29 & 1 & & \\
\hline & 30 & & 1 & \\
\hline \multirow{2}{*}{16} & 31 & & & 1 \\
\hline & 32 & 1 & & \\
\hline \multirow{2}{*}{17} & 33 & 1 & & \\
\hline & 34 & & 1 & \\
\hline \multirow{2}{*}{18} & 35 & 1 & & \\
\hline & 36 & & 1 & \\
\hline \multirow{2}{*}{19} & 37 & 1 & & \\
\hline & 38 & & 1 & \\
\hline \multirow{2}{*}{20} & 39 & 1 & & \\
\hline & 40 & & & 1 \\
\hline \multirow{2}{*}{21} & 41 & 1 & & \\
\hline & 42 & & 1 & \\
\hline \multirow{2}{*}{22} & 43 & 1 & & \\
\hline & 44 & & 1 & \\
\hline \multirow{2}{*}{23} & 45 & & & 1 \\
\hline & 46 & 1 & & \\
\hline \multirow{2}{*}{24} & 47 & 1 & & \\
\hline & 48 & & 1 & \\
\hline \multirow{2}{*}{25} & 49 & 1 & & \\
\hline & 50 & & 1 & \\
\hline \multirow{2}{*}{26} & 51 & 1 & & \\
\hline & 52 & & 1 & \\
\hline \multirow{2}{*}{27} & 53 & 1 & & \\
\hline & 54 & & 1 & \\
\hline
\end{tabular}

\subsection{Instance II}

In Instance II, some simplifications had to be made due to the relation between the monthly demands and the storage capacities of the facilities. There are facilities that have a storage capacity smaller than its product consumption in a month and, therefore, have to be visited more than once during a month. It is assumed that the facilities requiring more than one visit in the month will be visited fortnightly. Thus, two sets that constitute two different instances of the same problem are formed. One set includes only the facilities that require a reinforcement visit in the middle of the month, i.e., a "reinforcement" schedule. The other one is constituted by all the facilities, i.e., it is the "complete" schedule. For the facilities that belong to both sets, their monthly demand is divided to be expressed in a biweekly basis. With this strategy the problem can be conceived as being two separated problems. For the complete instance, the 702 facilities are reduced to 234 clusters in the first stage and, finally, 34 routes are built. Seventeen chemical products from the four system codes are demanded. The description of the different measured times and the demand products is presented in Table 4 while the schedule for each truck along the planning horizon is outlined in Table 5. 
Table 4

Description of routes in solution of Instance II: complete schedule

\begin{tabular}{|c|c|c|c|c|c|c|c|c|}
\hline Route & $\begin{array}{c}\text { Number } \\
\text { of }\end{array}$ & $\begin{array}{c}\text { Total time } \\
(\mathrm{min})\end{array}$ & $\begin{array}{c}\text { Service } \\
\text { time }\end{array}$ & $\begin{array}{c}\text { Transport } \\
\text { time }\end{array}$ & $\begin{array}{c}\text { Loading } \\
\text { time }\end{array}$ & $\begin{array}{l}\text { Demand } \\
\text { in barrels }\end{array}$ & $\begin{array}{c}\text { System } \\
\text { Code }\end{array}$ & $\begin{array}{c}\text { Number } \\
\text { of }\end{array}$ \\
\hline 1 & 1 & 445 & 133 & 213 & 100 & 20 & 0 & 1 \\
\hline 2 & 11 & 447 & 136 & 195 & 115 & 23 & 0 & 4 \\
\hline 3 & 9 & 447 & 166 & 151 & 130 & 26 & 0 & 3 \\
\hline 4 & 17 & 447 & 149 & 178 & 120 & 24 & 0 & 4 \\
\hline 5 & 8 & 448 & 146 & 177 & 125 & 25 & 0 & 6 \\
\hline 6 & 0 & 421 & 145 & 166 & 110 & 22 & 1 & 1 \\
\hline 7 & 8 & 448 & 145 & 183 & 120 & 24 & 0 & 3 \\
\hline 8 & 0 & 433 & 132 & 201 & 100 & 20 & 1 & 1 \\
\hline 9 & 13 & 450 & 160 & 165 & 125 & 25 & 0 & 3 \\
\hline 10 & 6 & 449 & 119 & 235 & 95 & 19 & 0 & 4 \\
\hline 11 & 20 & 442 & 180 & 122 & 140 & 28 & 0 & 5 \\
\hline 12 & 6 & 406 & 164 & 111 & 130 & 26 & 0 & 5 \\
\hline 13 & 4 & 450 & 108 & 252 & 90 & 18 & 0 & 5 \\
\hline 14 & 11 & 449 & 136 & 202 & 110 & 22 & 0 & 3 \\
\hline 15 & 12 & 446 & 141 & 190 & 115 & 23 & 0 & 3 \\
\hline 16 & 0 & 398 & 174 & 84 & 140 & 28 & 3 & 4 \\
\hline 17 & 5 & 444 & 154 & 165 & 125 & 25 & 0 & 5 \\
\hline 18 & 13 & 441 & 152 & 165 & 125 & 25 & 0 & 4 \\
\hline 19 & 3 & 446 & 95 & 271 & 80 & 16 & 0 & 3 \\
\hline 20 & 15 & 412 & 180 & 93 & 140 & 28 & 0 & 4 \\
\hline 21 & 17 & 449 & 161 & 158 & 130 & 26 & 0 & 3 \\
\hline 22 & 0 & 446 & 78 & 309 & 60 & 12 & 0 & 2 \\
\hline 23 & 10 & 449 & 138 & 201 & 110 & 22 & 0 & 4 \\
\hline 24 & 0 & 440 & 121 & 219 & 100 & 20 & 3 & 4 \\
\hline 25 & 0 & 441 & 112 & 235 & 95 & 19 & 0 & 4 \\
\hline 26 & 0 & 446 & 109 & 247 & 90 & 18 & 3 & 4 \\
\hline 27 & 15 & 449 & 114 & 240 & 95 & 19 & 0 & 4 \\
\hline 28 & 16 & 435 & 131 & 204 & 100 & 20 & 0 & 1 \\
\hline 29 & 0 & 294 & 52 & 202 & 40 & 8 & 0 & 1 \\
\hline 30 & 11 & 410 & 164 & 111 & 135 & 27 & 0 & 5 \\
\hline 31 & 0 & 436 & 134 & 192 & 110 & 22 & 3 & 4 \\
\hline 32 & 0 & 450 & 97 & 273 & 80 & 16 & 0 & 3 \\
\hline 33 & 6 & 259 & 39 & 185 & 35 & 7 & 0 & 4 \\
\hline 34 & 2 & 284 & 26 & 238 & 20 & 4 & 0 & 1 \\
\hline
\end{tabular}

Table 5

Solution of Instance II: complete schedule

\begin{tabular}{|c|c|c|c|c|}
\hline \multirow{2}{*}{ Day } & \multirow{2}{*}{ Route } & \multicolumn{3}{|c|}{ Truck } \\
\hline & & T1 & $\mathbf{T 2}$ & T3 \\
\hline \multirow{2}{*}{1} & 1 & 1 & & \\
\hline & 2 & 1 & & \\
\hline \multirow{2}{*}{2} & 3 & 1 & & \\
\hline & 4 & & 1 & \\
\hline \multirow{2}{*}{3} & 5 & 1 & & \\
\hline & 6 & & 1 & \\
\hline \multirow{2}{*}{4} & 7 & 1 & & \\
\hline & 8 & & 1 & \\
\hline \multirow{2}{*}{5} & 9 & 1 & & \\
\hline & 10 & & 1 & \\
\hline \multirow{2}{*}{6} & 11 & & & 1 \\
\hline & 12 & & 1 & \\
\hline \multirow{2}{*}{7} & 13 & 1 & & \\
\hline & 14 & & 1 & \\
\hline \multirow{2}{*}{8} & 15 & 1 & & \\
\hline & 16 & & & 1 \\
\hline \multirow{2}{*}{9} & 17 & 1 & & \\
\hline & 18 & & 1 & \\
\hline
\end{tabular}

\begin{tabular}{ccccc}
\hline \multirow{2}{*}{ Day } & \multirow{2}{*}{ Route } & \multicolumn{3}{c}{ Truck } \\
\cline { 3 - 5 } 10 & 19 & 1 & T2 & T3 \\
\hline \multirow{2}{*}{11} & 20 & & 1 & \\
& 21 & 1 & & \\
\multirow{2}{*}{12} & 22 & & 1 & \\
\hline \multirow{2}{*}{13} & 24 & 1 & & \\
\multirow{2}{*}{14} & 25 & 1 & & \\
\hline \multirow{2}{*}{15} & 26 & & & \\
\hline \multirow{2}{*}{16} & 28 & & & \\
\hline \multirow{2}{*}{17} & 30 & & & \\
\hline
\end{tabular}


In the reinforcement instance, with an initial number of 35 facilities, 11 clusters and 6 routes are constructed. These routes demanded ten chemical products from the four system codes. The description of the routes is presented in Table 6 while the schedule for the trucks is in Table 7.

Table 6

Description of routes in solution of Instance II: reinforcement schedule

\begin{tabular}{ccccccccc}
\hline Route & $\begin{array}{c}\text { Number } \\
\text { of }\end{array}$ & $\begin{array}{c}\text { Total time } \\
\text { (min) }\end{array}$ & $\begin{array}{c}\text { Service } \\
\text { time }\end{array}$ & $\begin{array}{c}\text { Transport } \\
\text { time }\end{array}$ & $\begin{array}{c}\text { Loading } \\
\text { time }\end{array}$ & $\begin{array}{c}\text { Demand } \\
\text { in barrels }\end{array}$ & $\begin{array}{c}\text { System } \\
\text { Code }\end{array}$ & $\begin{array}{c}\text { Number } \\
\text { of }\end{array}$ \\
\hline 1 & 9 & 444 & 158 & 166 & 120 & 24 & 1 & 2 \\
2 & 4 & 377 & 96 & 206 & 75 & 15 & 1 & 2 \\
3 & 8 & 422 & 114 & 213 & 95 & 19 & 3 & 5 \\
4 & 2 & 291 & 49 & 202 & 40 & 8 & 3 & 3 \\
5 & 5 & 318 & 41 & 242 & 35 & 7 & 2 & 2 \\
6 & 7 & 292 & 41 & 211 & 40 & 8 & 0 & 4 \\
\hline
\end{tabular}

Table 7

Solution of Instance II: reinforcement schedule.

\begin{tabular}{|c|c|c|c|c|}
\hline \multirow{2}{*}{ Day } & \multirow{2}{*}{ Route } & \multicolumn{3}{|c|}{ Truck } \\
\hline & & T1 & T2 & T3 \\
\hline \multirow{2}{*}{1} & 1 & 1 & & \\
\hline & 2 & & 1 & \\
\hline \multirow{2}{*}{2} & 3 & 1 & & \\
\hline & 4 & & 1 & \\
\hline \multirow{2}{*}{3} & 5 & 1 & & \\
\hline & 6 & & 1 & \\
\hline
\end{tabular}

\section{Conclusion and further research}

The upstream transport logistics in oil industries that operate inland has not yet been thoroughly studied. This paper addressed such a problem in a company with a particular distribution planning problem where the sites to be supplied vary due to operational conditions. This case has presented specific technical and labor constraints, e.g., products that cannot be transported jointly in the same trip and a limited fleet and number of drivers. This article proposes a novel mixed-integer programming formulation for this problem. Moreover, a constructive heuristic to solve this problem is devised. Real-world instances provided by the company including up to 700 facilities (demand points) were solved. The proposed heuristic allows the automatization of the decision-making process reducing the time required to build a feasible plan. As a lateral consequence, the geo-localization of the bases was useful for the company to improve the estimation of the travel time of the routes. Main lines for future work include trying to improve the solution strategy with the inclusion of more powerful mataheuristics, as for instance, simulating annealing. This algorithm can start from the proposed solution and improve it. However, to achieve this the input information should be enhanced since the improvements should exhibit a larger sensitivity than the one that is currently obtainable with the formula for travel times developed by the company.

Therefore, designing better procedures to help the company obtain more precise information also constitutes a major line for future work. These procedures can include, in a first stage, the digital mapping of the network of paths between the different bases in order to have more precise knowledge of the distances between them, improving the formula of travel time estimation. The same procedure, applied to the facilities (and the roads connecting them to the bases) is far from being feasible for Small and Medium Enterprises like the target company in this work. The reason is the continuous variation of the locations of the extensive network of oil wells and internal paths due to operational reasons. Thus, digitalization would require a large investment in Information and Communication Technologies and/or of personnel that has to be to this task. 


\section{References}

Aas, B., Gribkovskaia, I., Halskau Sr, Ø., \& Shlopak, A. (2007). Routing of supply vessels to petroleum installations. International Journal of Physical Distribution \& Logistics Management, 37(2), 164179.

Aas, B., Halskau Sr, Ø., \& Wallace, S. W. (2009). The role of supply vessels in offshore logistics. Maritime Economics \& Logistics, 11(3), 302-325.

Brešić, J., Knežević, B., Milošević, M., Tomljanović, T., Golubović, R., \& Mustajbegović, J. (2007). Stress and work ability in oil industry workers. Archives of Industrial Hygiene and Toxicology, 58(4), 399-405. Cuesta, E. F., Andersson, H.,

Cuesta, E. F., Andersson, H., Fagerholt, K., \& Laporte, G. (2017). Vessel routing with pickups and deliveries: an application to the supply of offshore oil platforms. Computers \& Operations Research, 79, 140-147.

Dempster, M. A. H., Pedron, N. H., Medova, E. A., Scott, J. E., \& Sembos, A. (2000). Planning logistics operations in the oil industry. Journal of the Operational Research Society, 51(11), 1271-1288.

Ebrahimi, S. M., Koh, S. C. L., Genovese, A., \& Kumar, N. (2018). Structure-integration relationships in oil and gas supply chains. International Journal of Operations \& Production Management, 38(2), 424-445.

Fagerholt, K., \& Lindstad, H. (2000). Optimal policies for maintaining a supply service in the Norwegian Sea. Omega, 28(3), 269-275.

Fera, M., Fruggiero, F., Lambiase, A., Macchiaroli, R., \& Miranda, S. (2017). The role of uncertainty in supply chains under dynamic modeling. International Journal of Industrial Engineering Computations, 8(1), 119-140.

Friedberg, D. O., \& Uglane, V. T. (2013). Routing and Scheduling of Platform Supply Vessels: Case from the Brazilian Petroleum Industry (Master's thesis, Institutt for industriell økonomi og teknologiledelse).

Fritz, M. M. C., \& Silva, M. E. (2018). Exploring supply chain sustainability research in Latin America. International Journal of Physical Distribution \& Logistics Management, 48(8), 818-841.

Gligor, D., Gligor, N., Holcomb, M., \& Bozkurt, S. (2019). Distinguishing between the concepts of supply chain agility and resilience: A multidisciplinary literature review. The International Journal of Logistics Management, 30(2), 467-487.

Halvorsen-Weare, E. E., Fagerholt, K., Nonås, L. M., \& Asbjørnslett, B. E. (2012). Optimal fleet composition and periodic routing of offshore supply vessels. European Journal of Operational Research, 223(2), 508-517.

Helsgaun, K. (2000). An effective implementation of the Lin-Kernighan traveling salesman heuristic. European Journal of Operational Research, 126(1), 106-130.

Hussain, R. A. E. D., Assavapokee, T. I. R. A. V. A. T., \& Khumawala, B. (2006). Supply chain management in the petroleum industry: challenges and opportunities. International Journal of Global Logistics \& Supply Chain Management, 1(2), 90-97.

Kaiser, M. J. (2010). An integrated systems framework for service vessel forecasting in the Gulf of Mexico. Energy, 35(7), 2777-2795.

Kisialiou, Y., Gribkovskaia, I., \& Laporte, G. (2018a). The periodic supply vessel planning problem with flexible departure times and coupled vessels. Computers \& Operations Research, 94, 52-64.

Kisialiou, Y., Gribkovskaia, I., \& Laporte, G. (2018b). Robust supply vessel routing and scheduling. Transportation Research Part C: Emerging Technologies, 90, 366-378.

Lin, S., \& Kernighan, B. W. (1973). An effective heuristic algorithm for the traveling-salesman problem. Operations research, 21(2), 498-516.

Lopez Cattaneo, A. (2009). Los riesgos laborales en la actividad petrolera. Available at: https://estrucplan.com.ar/articulos/los-riesgos-laborales-en-la-actividad-petrolera (accessed 9 May 2019).

Maisiuk, Y., \& Gribkovskaia, I. (2014). Fleet sizing for offshore supply vessels with stochastic sailing and service times. Procedia Computer Science, 31, 939-948. 
Milaković, A. S., Ulstein, M., Bambulyak, A., \& Ehlers, S. (2015, October). Optimization of OSV fleet for an offshore oil and gas field in the Russian Arctic. In ASME 2015 34th International Conference on Ocean, Offshore and Arctic Engineering. American Society of Mechanical Engineers Digital Collection.

Miller, C. E., Tucker, A. W., \& Zemlin, R. A. (1960). Integer programming formulation of traveling salesman problems. Journal of the ACM (JACM), 7(4), 326-329.

Nesmachnow, S. (2014). An overview of metaheuristics: accurate and efficient methods for optimisation. International Journal of Metaheuristics, 3(4), 320-347.

Nitsche, B., \& Durach, C. F. (2018). Much discussed, little conceptualized: supply chain volatility. International Journal of Physical Distribution \& Logistics Management, 48(8), 866-886.

Shyshou, A., Gribkovskaia, I., Laporte, G., \& Fagerholt, K. (2012). A large neighbourhood search heuristic for a periodic supply vessel planning problem arising in offshore oil and gas operations. INFOR: Information Systems and Operational Research, 50(4), 195-204.

Singh, H., Garg, R., \& Sachdeva, A. (2018). Supply chain collaboration: A state-of-the-art literature review. Uncertain Supply Chain Management, 6(2), 149-180.

Toncovich, A., Rossit, D., \& Frutos M., \& Rossit D. G. (2019). Solving a multi-objective manufacturing cell scheduling problem with the consideration of warehouses using a simulated annealing based procedure. International Journal of Industrial Engineering Computations, 10(1), 1-16.

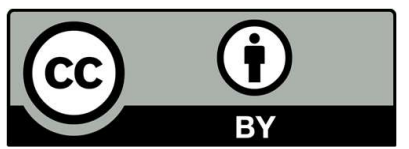

(C) 2020 by the authors; licensee Growing Science, Canada. This is an open access article distributed under the terms and conditions of the Creative Commons Attribution (CCBY) license (http://creativecommons.org/licenses/by/4.0/). 